\title{
El capitalismo, su origen y configuración moderna
}

\section{Prof. Fernando GUTIÉRREZ RODRÍGUEZ}

Parece extraña la afirmación del biólogo G. Wolf, que rechaza la teoría de la evolución de las especies de Darwin. Para Wolf la selección es natural. No obstante que la mayoría de biólogos aceptan la teoría de Darwin, es decir el fenómeno de las mutaciones espontáneas. Hay motivos para ver en esta teoría un caso claro de la alienación que, siguiendo las ideas de Marx encontramos en varias otras manifestaciones de la cultura moderna nacida de y como consecuencia de la implantación del capitalismo en el temprano renacimiento. Disponemos de numerosos e importantes estudios, que han utilizado algunas ideas de Marx para ofrecer nuevos y aclaradores enfoques sobre temas tan importantes, como por ejemplo, el arte moderno, el que siguió inmediatamente al renacentista, por tanto, después de 1550 . Se trataría en este caso de una alienación causada por las nuevas realidades, las nuevas actitudes y las nuevas actividades del hombre, en concreto por la nueva praxis mercantil. Es decir, las características del "Pícaro", sus prácticas y tretas que rayan a veces en la delincuencia, sin caer jamás en ella, pero las consideramos a la luz de las prácticas del mercader. Concretamente, los mercaderes genoveses, con moral ambivalente y de doble faz, que trajo el mercantilismo ocasionando cambios tal vez no excesivamente llamativos, pero sí profundos y duraderos.

Así, tenemos por ejemplo, la presentación exacta y precisa de los hechos que conocemos y luego veremos las consecuencias que de ellos se derivan. $\mathrm{Y}$ en este sentido, podemos asegurar que los mercaderes florentinos eran capaces, ya a mediados del Siglo XV, de calcular por adelantado y con precisión, los periodos regularmente repetidos, es decir, en forma cíclica y fluctuante, en los que habría escasez o abundancia de dinero en las distintas plazas donde acostumbraban a operar, Medina, Frankfurt, Amberes. El mercado moderno es cálculo y el cálculo, el único medio de racionalizar la actividad y determinar la deseada ganancia. Tenemos, pues, aquí el origen del moderno capitalismo. Y éste está determinado en parte, por la gran cantidad de metales preciosos que afluían de América. Así lo vio Marx, en su interesante obra "Miseria de la Filosofía" (1847) No fue, sin embargo, la mera afluencia de metales preciosos, en sí misma, la que creó el nuevo orden. Fue, más bien, el cambio 
de las actitudes y de la actividad del propio hombre. Si de algo se puede decir que es obra, creación del hombre, este algo sería el capitalismo. Ninguna cosa, fuera de él, lo explica. Ni la riqueza de bienes, ni la carencia de ellos. El "System of Wants" de Adam Smith, percibido y sentido, es lo que produce el "Wealth of the Nations". En este sentido, queremos reseñar aquí la opinión del conocido economista Braudel, que quiere distinguir con claridad un periodo de economía de mercado, a lo mucho, capitalismo incipiente, y el capitalismo moderno, capitalismo propiamente dicho el que se da ahora y se dio ya con la revolución industrial inglesa, en la segunda mitad del Siglo XIX. Ofreceremos más adelante algunas consideraciones sobre este punto. Sin embargo, en contra de lo que cabría esperar, esa incipiente economía de mercado se afirmó, estableció y expandió rápidamente en el curso de pocos años y fue capaz de originar cambios tan profundos en la fisonomía del hombre, que realmente nos asombran. Por otro lado, encontramos ya entonces, y plenamente desarrollados, ciertos fenómenos, que aun ahora nos parecen exclusivos de nuestra época, definitorios de la misma. Y sin embargo, los encontramos allí. Pensamos ahora por ejemplo, en la especulación planificada, en las "Multinationals", en el “crédito' y su papel central en la vida económica de los individuos, dentro del capitalismo de nuestros días y en ciertos países, en el establecimiento de un mercado mundial o globalizado. Se dio entonces, en verdad, una verdadera revolución de los valores, que trataremos de comprender $\mathrm{y}$, al hacerlo, nos vienen a la mente las patéticas y, según él, proféticas palabras de Nietzsche, la trasmutación de todos los valores.

Afirma Arnold Hauser lo siguiente: "Es la nueva praxis la que allanó el camino a la nueva lógica y a la nueva moral y no al revés". Tratemos de verlo en detalle. Los mercaderes florentinos y genoveses, al calcular la abundancia o escasez, de dinero, en las distintas plazas donde acostumbraban a operar, hubieron de tener también en cuenta lo que hoy llamamos la "coyuntura". A tenor de la teoría cuantitativista del mercado, de acuerdo a la cual operaban ellos. Ahora es, pues, la coyuntura, el mercado, por tanto, quien determina el precio de los artículos. El "mercado", entidad anónima, oscuro poder, es quien manda. Ya no se puede seguir hablando del valor "intrínseco" de las cosas, como creían los hombres, los artesanos y artistas del medioevo. Esta fe en el valor intrínseco de alguna cosa, se desvaneció. El que hoy hable del valor "intrínseco" del algo, y también de "alguien", será llamado, cuando menos, conservador. Tampoco el hombre o las cosas que le pertenecen "valen", digamos, mejor dicho, valen por sí mismos. Valen, más bien, en función de la valoración que reciben, que proviene de un "algo" sobre el que no tenemos ningún poder. Finalmente, es obvio que a la creencia en el valor intrínseco de las cosas, corresponde una moral de preceptos invariables, y de validez universal, válida para todos. Ahora, las cosas no valen ya por lo que valen en sí mismas sino por una especie de valor basado en la "cotización". Y en este sentido debo reconocer que siempre me ha causado 
sorpresa y cuando oigo hablar del "alza" de alguien en la cotización que alcanza o va alcanzando en el mercado de valores. Fulano es "The one to watch"!, como si dijéramos: "síganle la pista", cuenten con él, arrimense a él, que éste ya es "in". Ahora comprendemos el origen de toda esta jerga.

Aún queda por mencionar un aspecto importante en lo que venimos tratando. La Iglesia había condenado la usura a lo largo de los siglos. Las nuevas realidades, en cambio, impusieron otra cosa. La acumulación de capitales llevó inexorablemente a la creación de la banca. Pronto tendremos un encuentro con la banca de entonces, ni menos poderosa, ni menos inexorable que la de hoy. Y la banca llegó a ser el gran protagonista del acontecer público, no los reyes. Y el dinero de los banqueros sustentó tantas guerras. Los préstamos de dinero, por su parte, hicieron ver, de forma implacable, sus exigencias. Incluso el humilde prestamista experimentó en sí mismo el cómo y el porqué de la legitimidad y licitud de la usura. En la nueva situación, creada por el mercado, por la economía de mercado, por ejemplo, hoy, 50 de los dólares recibidos en préstamo, al tiempo que se aplaza la devolución de los 50 restantes, 30 ó 60 días, limita al prestamista en sus posibilidades de invertir o comprar, en una palabra, le limita en el uso de su dinero, en otros términos, la dilación en la devolución del dinero, significa para él pérdida real. También el prestamista depende de la coyuntura y está sujeto a ella.

La Iglesia, de suyo y desde sus principios, no podía comprender, esta exigencia impuesta por la realidad de los mercados, o dicho de otra forma, por las prácticas de los mercaderes. Y en consecuencia, a despecho de las enseñanzas de la Iglesia, y de los preceptos de los concilios que explícitamente prohibían la usura, incluso los "hombres de buena conciencia". La usura se convirtió en práctica habitual, a la que nadie escapaba. En resumen, la nueva praxis abrió el camino a la nueva moral. Las nuevas formas de vida se habían impuesto también en este terreno y se admitió la licitud de la usura, lo que, en el parecer de los economistas Mos y Ryan, allanó el camino para el mercado moderno.

Una de las características de la Edad Media, es la existencia de héroes y santos, que gozaban del reconocimiento universal. Sería erróneo pensar que ya no hay valores morales, ni hombres que viven de acuerdo con ello. Los hay y tal vez abunden. Lo que no hay ya son normas o valores de validez universal, aceptados por todos. Hay aún una moral, pues el ser moral es algo que define al hombre. Pero lo que tenemos hoy es más bien una moral de andar por casa, una moral de alcance únicamente individual, personal. Lo que para uno es virtud, puede ser reprobable o menos bueno para otro. En el orden social, murió el Caballero y nació el soldado. Soldado es como dice su nombre el que lucha o pelea a sueldo, por dinero, no por convicciones. Así nació el ejército. En la nuestra época podemos observar la capacidad de destrucción que lleva en sí el 
ejército. El ejército es algo totalmente nuevo. Nos recuerda ciertamente a las legiones romanas. Pero las nuevas armas de pólvora y tecnológicas confirieron una capacidad de destrucción que los romanos no hubieran podido soñar. Y permítanme que mencione un dato, aislado, pero muy importante. A la luz de esta nueva realidad, el ejército, nació la Compañía de Jesús, fundada por el Caballero Ignacio de Loyola. Pero recuerden solo que esta Compañía tiene un modelo concreto: el ejército. Compañía, era. en efecto, el cuerpo de ejército mandado por un capitán. "Y nuestro Capitán - escribió San Ignacio - es Cristo" Y hay algo peor, la doble moral. La moral de los que condenan a Ben Laden como terrorista reprobable, mientras veneran como héroe al pirata Drake o Draque. En general, se ha impuesto ya el realismo político, o la ley de que el bien justifica los medios. A esto nos han llevado las nuevas formas de vida, la nueva praxis.

No termina aquí todo. El racionalismo, como forma de vida, e incluso como forma de comprender la realidad, como forma de negociar con ella, precedió a su formulación teórica, atribuida a Descartes. La racionalización y el cálculo de la riqueza, permitieron las grandes operaciones que se llevaron a cabo con el dinero. Maravall ha puesto en relación de dependencia el espíritu y el método matemático de la ciencia de Galileo con respecto a las operaciones de cálculo que venían haciendo desde mucho antes, los mercaderes y banqueros en la vida cotidiana. Es una vez más, la nueva praxis.

Con ser esto -lo que llevamos dicho- realmente sorprendente, no nos da aún idea de una nueva praxis que domina hoy. Citaremos solo dos ejemplos. Podemos decir a grandes rasgos que la expansión del capitalismo tuvo lugar durante el reinado del Emperador Carlos V. Hasta entonces Carlos I Rey de España, aspiraba por derecho legítimo -según el derecho y las leyes vigentes de la época- a la corona del Imperio, el Sacro Imperio Romano Germánico, como primer descendiente del Emperador Maximiliano I, abuelo suyo, muerto ya para entonces en Alemania. La elección estaba pendiente de ratificación por parte de los Príncipes Electores. Y éstos, viendo la coyuntura y dispuestos a sacar provecho de ella, decidieron poner a subasta la corona Imperial. El primer contendiente a la corona era, por supuesto, el Rey de España Carlos I. Sin embargo, el Rey Francisco I de Francia, sin título legítimo, ni dinero para "comprarla" presentó su candidatura. Y los Príncipes Electores, que vieron la ocasión de oro, decidieron otorgársela a quien legítimamente le correspondía, es decir, el Rey Carlos I. Sin embargo, dejando de lado la ley inmemorial, que debieran haber acatado, pusieron un precio a la Corona. El precio fue muy alto, altísimo. Carlos I no tenía absolutamente dinero para pagarla, pero, fijémonos bien, tenía crédito, porque Hernán Cortés acababa de emprender la conquista de México. Y en consecuencia, los banqueros alentados por este crédito adelantaron los 858,000 florines oro de 22 kilates, a un interés del 18\% 
anual. Y fue de la siguiente forma, los banqueros italianos, es decir, florentinos y genoveses, adelantaron 165.000 florines; 150,000 adelantaron los Welser (elevados también a la nobleza en 1532) y 543,000 florines le adelantó Jacobo Fúcar el Rico, que como los Welser, era alemán. Ni el Emperador, ni su hijo Felipe II fueron capaces nunca de satisfacer tamaña deuda. El emperador pasaba apuros económicos, quien para satisfacer momentáneamente la deuda contraída con los Fúcar, y las presiones de estos, se vio obligado a enajenar nada menos que toda una provincia del Imperio, es decir, Venezuela. De lo dicho, se deduce claramente el verdadero sentido y alcance de la explotación del oro y la plata de América. Fue ya en aquellos años, una explotación capitalista a gran escala, a escala mundial.

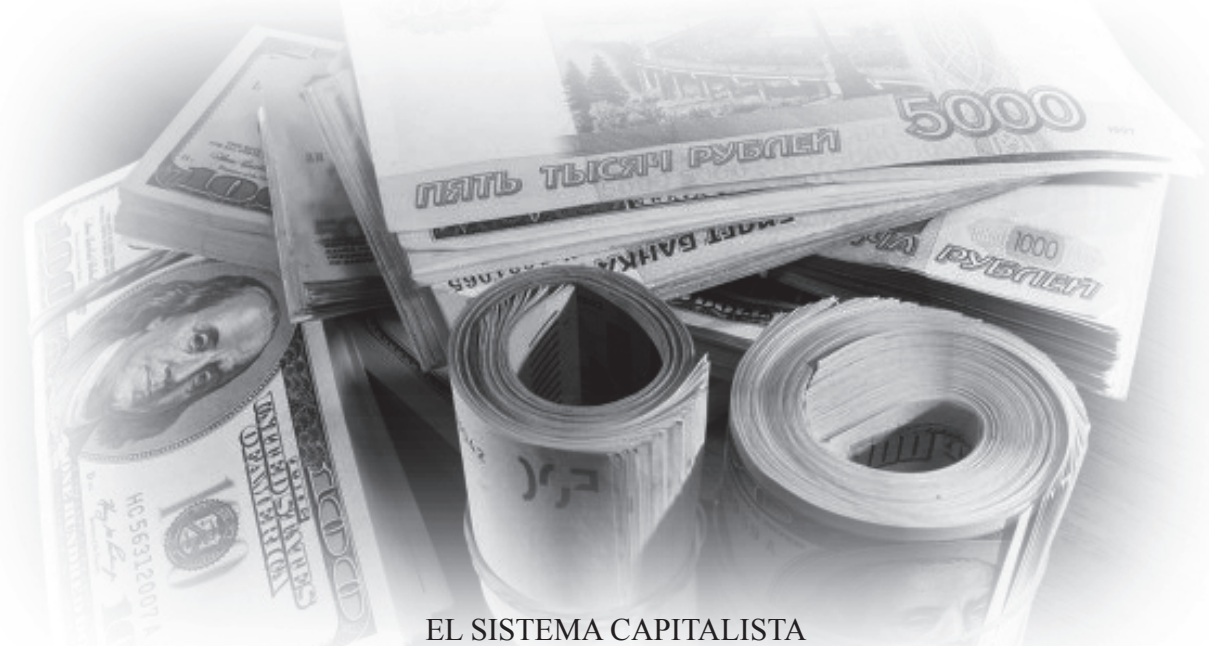

Las guerras entre Carlos V y Francisco I de Francia llenaron el primer cuarto del siglo XVI. Los ejércitos del Emperador estaban estacionados al norte de Italia, en espera de recibir órdenes de su jefe, porque Francisco I había retado al Emperador a una batalla. Era el año 1521, Europa entera estaba pendiente de esta contienda. Pero quienes la seguían con mayor atención resultaron ser los banqueros ingleses. Sabían estos, en efecto, que si el Emperador nombraba general al Gran Capitán Francisco Fernández de Córdoba, Francisco I perdería no solo la batalla, sino su persona, pues el Gran Capitán le haría prisionero y el Emperador pediría un altísimo rescate por él. Todo sucedió como los banqueros ingleses habían calculado. Fue esta una operación financiera de primerísimo orden, aprovechando la coyuntura que se les ofrecía. Me veo forzado a admitir que la economía de mercado dominante en Europa, desde el siglo XV y expandida en los dos siglos siguientes, XVI y XVII, ostenta todas las características y propiedades del capitalismo que vino después. No es 
un capitalismo más o menos incipiente o rudimentario. Sin embargo, merecen consideración las apreciaciones de Braudel "El capitalismo continua apoyándose en la explotación de los recursos y de las posibilidades internacionales, dicho de otro modo, abarca las dimensiones del mundo, cuando menos, tiende al mundo entero"... y se apoya siempre, obstinadamente, en los monopolios de derecho o de hecho, a pesar de las violencias desencadenadas contra él por este motivo".

\section{Bibliografía}

Dr. Francisco Fernández Turienzo. University of Massachusetts, Harvard University.

Fernando Braudel. La Dinámica del capitalismo. FCE.

Carlos Marx. El Capital.

Carlos Marx. Miseria de la filosofía.

Adam Smith. La riqueza de las naciones. 